\title{
Erratum to: Biosorption of Copper by Cyanobacterial Bloom-Derived Biomass Harvested from the Eutrophic Lake Dianchi in China
}

Kan Wang • Giovanni Colica • Roberto De Philippis • Yongding Liu $\cdot$ Dunhai Li

Published online: 3 November 2010

(C) Springer Science+Business Media, LLC 2010

Erratum to: Curr Microbiol

DOI 10.1007/s00284-010-9617-2

The original version of this article unfortunately contained a mistake. Due to our mistake, Dr. Giovanni Colica and
Dr. Roberto De Philippis were missed in the author list. The proper list of Authors is mentioned here.

The online version of the original article can be found under doi:10.1007/s00284-010-9617-2.

K. Wang · Y. Liu · D. Li ( $ه)$

Institute of Hydrobiology, The Chinese Academy of Sciences,

7 South Donghu Road, 430072 Wuhan, Wuchang District,

Hubei Province, People's Republic of China

e-mail: lidh@ihb.ac.cn

\section{K. Wang}

Graduate School of the Chinese Academy of Science,

100049 Beijing, People's Republic of China

G. Colica · R. De Philippis

Department of Agricultural Biotechnology, Florence University,

Piazzale delle Cascine 24, I-50144 Firenze, Italy

e-mail: giovanni.colica@unifi.it

R. De Philippis

e-mail: roberto.dephilippis@unifi.it 